\title{
Synthesis and structural characterization of copper(II) complexes with a tetradentate semicarbazone ligand derived from 2,5-hexadione
}

\author{
Rasoul Vafazadeh ${ }^{1}\left[\right.$ - Mahboobeh Ehsani ${ }^{1} \cdot$ Anthony C. Willis ${ }^{2}$
}

Received: 23 October 2018 / Accepted: 17 June 2019 / Published online: 21 June 2019

(C) Iranian Chemical Society 2019

\begin{abstract}
Four $\mathrm{Cu}(\mathrm{II})$ complexes $\left[\mathrm{CuLH}_{2} \mathrm{O}\right]\left(\mathrm{ClO}_{4}\right)_{2}, \mathbf{1}$; $[\mathrm{CuLCl}] \mathrm{Cl} . \mathrm{H}_{2} \mathrm{O}, \mathbf{2}$; $[\mathrm{CuLBr}]_{2}\left(\mathrm{Cu}_{3} \mathrm{Br}_{5}\right), \mathbf{3}$; and $\left[\mathrm{CuLH}_{2} \mathrm{O}\right]\left(\mathrm{NO}_{3}\right)_{2}, \mathbf{4}$; where $\mathrm{L}=$ tetradentate semicarbazone ligand, have been synthesized and characterized by elemental analysis, FT-IR and UV-Vis. The structures of compounds $\mathbf{1}$ and $\mathbf{3}$ have been determined by single-crystal X-ray diffraction analyses. In mononuclear 1, the semicarbazone, $\mathrm{L}$ acts as a tetradentate neutral ligand and a water molecule also coordinates to the $\mathrm{Cu}$ atom. There are two independent $\left[\mathrm{CuL}\left(\mathrm{H}_{2} \mathrm{O}\right)\right]^{2+}$ cations and four perchlorate anions in the crystallographic asymmetric unit. One of the cations has a weak interaction between its $\mathrm{Cu}$ atom and a $\mathrm{O}$ atom of an adjacent perchlorate anion. The structure of 3 contains two independent $[\mathrm{CuLBr}]^{+}$cations and $\mathrm{a}\left(\mathrm{Cu}_{3} \mathrm{Br}_{5}\right)^{2-}$ anion. The coordination geometry around the cation's $\mathrm{Cu}$ (II) ion is five-coordinated square pyramidal, with $\mathrm{L}$ acting as a tetradentate neutral ligand and with a $\mathrm{Br}$ at the apical position. The $\mathrm{Cu}_{3} \mathrm{Br}_{5}^{2-}$ anions link to one another to form an infinite one-dimensional $\left(\mathrm{Cu}_{3} \mathrm{Br}_{5}^{2-}\right)_{\mathrm{n}}$ chain. Furthermore, the Hirshfeld surface analyses and the 2D fingerprint plot have been discussed.
\end{abstract}

Keywords Copper complex $\cdot$ Semicarbazone $\cdot 2,5$-Hexadione $\cdot$ Disorder $\cdot$ Tetradentate

\section{Introduction}

Studies of semicarbazone and thiosemicarbazone ligands and their complexes with transition and non-transition metals have received considerable attention, as they possess important biological properties and structural diversities [1-7]. The biological activity of the ligands is often increased upon coordination to transition metals [7-10].

Semicarbazone and thiosemicarbazone ligands are formed by condensation reactions between semicarbazide/thiosemicarbazide and relevant aldehydes or ketones [10-12]. Semicarbazone derivatives may have an advantage over their thiosemicarbazone analogues due to lower toxicity. However, the complexes of transition metals with bis(semicarbazone) have

Electronic supplementary material The online version of this article (https://doi.org/10.1007/s13738-019-01721-3) contains supplementary material, which is available to authorized users.

Rasoul Vafazadeh

rvafazadeh@yazd.ac.ir; rvafazadeh@gmail.com

Department of Chemistry, Yazd University, Yazd, Iran

2 Research School of Chemistry, Australian National

University, Canberra, ACT 2601, Australia been reported to have lower stability than the complexes of the analogous bis(thiosemicarbazone), which may be due to the fact that the bis(semicarbazone) can often undergo cyclization reactions, especially in the presence of metal ions [13-15]. Tetradentate bis(semicarbazone) ligands are prepared by condensation reaction of semicarbazide with 1 , 2-diketones, such as benzil in a 2:1 ratio $\left(\mathbf{L}^{\mathbf{1}}\right)$. They can lose one of their hydrazinic units to form a $\mathbf{L}^{2}$ ligand (Scheme 1) [14-16]. On the other, 1, 3-diketones usually exist predominantly as enol forms due to conjugation of the enol or enolate with the other carbonyl group. The semicarbazone ligands prepared by the condensation of 1, 3-diketones with semicarbazide mostly act as monoanionic tridentate ligands and coordinate to metal ions via a phenoxo or hydroxo oxygen, an imine nitrogen and an amide oxygen atoms (Scheme 1) [17-19].

In order to investigate the effect of the chain length of the diketone on the molecular structure of the semicarbazone complexes, we report the syntheses of several new copper(II) complexes, formed by the reaction of a neutral tetradentate semicarbazone derived from 2 equiv. of semicarbazide and 1 equiv. of 2,5-hexadione with copper(II) and various counter anions (Scheme 2). 


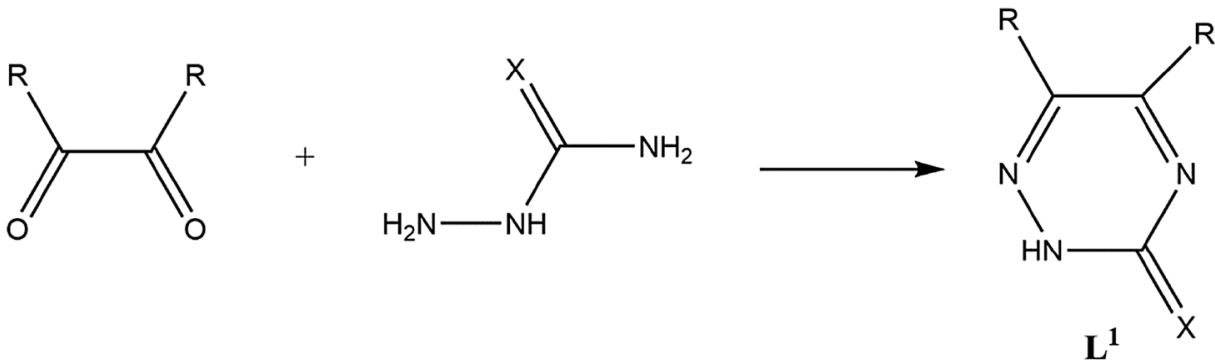

$\mathrm{R}=\mathrm{CH}_{3}$ and $\mathrm{Ph} \quad \mathrm{X}=\mathrm{O}$ and $\mathrm{S}$

$\mathbf{L}^{1}$

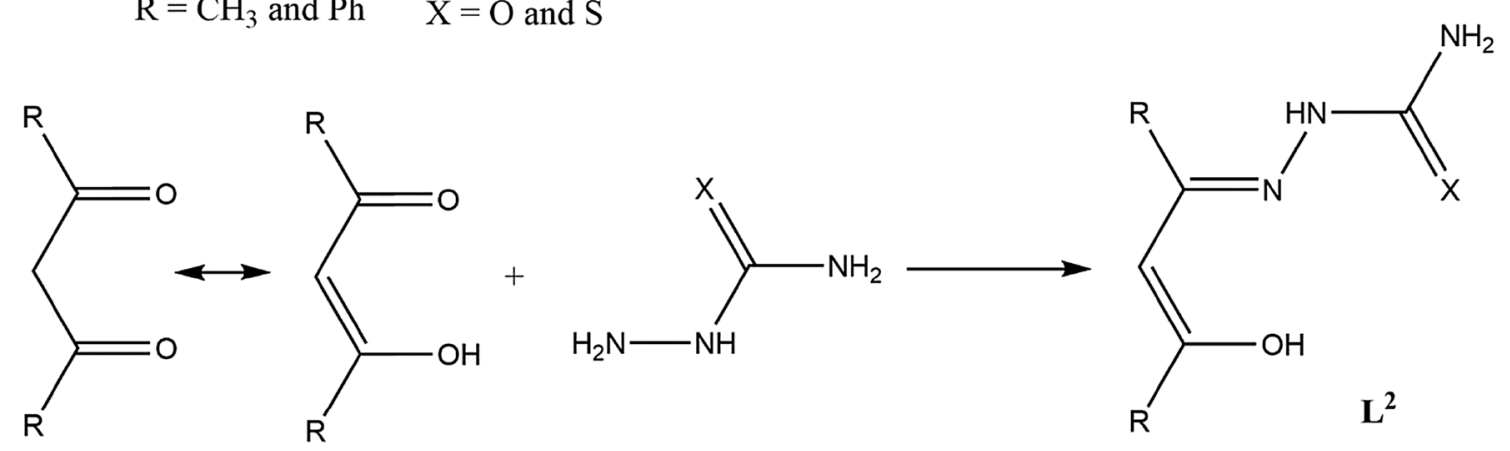

Scheme 1 Reaction of the 1,2-diketone and 1,3-diketone with semicarbazide<smiles>CC(=O)CCC(C)=O</smiles>

Scheme 2 Reaction of the 1,4 diketone with semicarbazide

\section{Experimental section}

\section{Starting materials}

All chemicals were of analytical reagent grade and were used without further purification.

\section{Physical measurements}

Infrared spectra were taken with an Equinox 55 Bruker FT-IR spectrometer using $\mathrm{KBr}$ pellets in the $400-4000 \mathrm{~cm}^{-1}$ range. Absorption spectra were determined in the solvent dimethylformamide (DMF) using GBC UV-Visible Cintra 101 spectrophotometer with $1 \mathrm{~cm}$ quartz, in the range 200-1000 nm. Elemental analyses (C,
$\mathrm{H}, \mathrm{N}$ ) were performed by using a CHNS-O 2400II PERKIN-ELMER elemental analyzer.

\section{X-ray crystallography}

Diffraction images were measured at $150 \mathrm{~K}$ on an Agilent SuperNova diffractometer using $\mathrm{CuK} \alpha(\lambda=1.54180 \AA)$ radiation. Data were extracted using the CrysAlis PRO package [20]. The structures were solved by direct methods with the use of SIR92 [21]. The structures were refined on $F^{2}$ by full matrix least-squares techniques using the CRYSTALS program package [22]. Atomic coordinates, bond lengths, and angles and displacement parameters have been deposited at the Cambridge Crystallographic Data Centre.

The $\mathrm{H}$ atoms were initially refined with soft restraints on the bond lengths and angles to regularize their geometry (C-H in the range $0.93-0.98 \AA, \mathrm{N}-\mathrm{H}=0.87 \AA, \mathrm{O}-\mathrm{H}=0.83$ 
$\AA$ ) and with $U_{\text {iso }}(\mathrm{H})$ in the range 1.2-1.5 times $U_{\text {eq }}$ of the parent atom. After this, the positions of the $\mathrm{H}$ atoms bonded to $\mathrm{O}$ and $\mathrm{N}$ were refined without constraints, whereas those bonded to $\mathrm{C}$ ride on the atoms to which they are bonded. Crystallographic data and refinement details for the complexes are given in Table 1. Details of the refinement procedures for the structures are given in the Supplementary Information.

Hirshfeld surfaces and the associated two-dimensional fingerprint plots for the complexes were calculated with CrystalExplorer 3.1 program [23]. The $d_{\text {norm }}$ surface and 2D fingerprint were used to analyses intermolecular interaction in the crystal packing.

\section{Syntheses}

\section{Synthesis of semicarbazone ligand, L}

The new tetradentate semicarbazone ligand $\mathrm{L}$ was synthesized by a general method as previously reported elsewhere by us and others $[24,25]$, by condensation of semicarbazide hydrochloride $(0.558 \mathrm{~g}, 5 \mathrm{mmol})$, sodium acetate $(0.410 \mathrm{~g}, 5 \mathrm{mmol})$ and 2,5 -hexadione $(0.3 \mathrm{ml}, 2.5 \mathrm{mmol})$ in an aqueous solution $(30 \mathrm{ml})$. The mixture was stirred at room temperature for $1 \mathrm{~h}$ during which a white precipitate was formed. The precipitate was filtered, washed with distilled water and dried at room temperature. The precipitate is insoluble in most common organic solvents such as methanol, ethanol, acetone, acetonitrile and dichloromethane and also is only very slightly soluble in DMF. Yield $47 \%$. Anal. Calcd. for $\mathrm{C}_{8} \mathrm{H}_{16} \mathrm{~N}_{6} \mathrm{O}_{2}: \mathrm{C}, 42.10 ; \mathrm{H}, 7.07 ; \mathrm{N}, 36.82$. Found: $\mathrm{C}, 42.28 ; \mathrm{H}, 7.15 ; \mathrm{N}, 37.05$. IR $\left(\mathrm{KBr}, \mathrm{cm}^{-1}\right): \mathrm{vC}=\mathrm{N}=1581$, vC $=\mathrm{O}=1683$.

\section{Synthesis of copper(II) complexes, 1-4}

$\mathrm{CuX}_{2} \cdot \mathrm{nH}_{2} \mathrm{O}\left(1 \mathrm{mmol}, X=\mathrm{ClO}_{4}, n=6,0.370 \mathrm{~g}, \mathbf{1} ; X=\mathrm{Cl}\right.$, $n=2,0.170 \mathrm{~g}, 2 ; X=\mathrm{Br}, n=0,0.224 \mathrm{~g}, \mathbf{3} ; X=\mathrm{NO}_{3}$, $n=3,0.242 \mathrm{~g}, 4$ ) was added to a stirred suspension of
Table 1 Crystallographic data of the complexes $\mathbf{1}$ and $\mathbf{3}$

\begin{tabular}{|c|c|c|}
\hline Compound & 1 & 3 \\
\hline Chemical formula & $\mathrm{C}_{8} \mathrm{H}_{18} \mathrm{Cl}_{2} \mathrm{CuN}_{6} \mathrm{O}_{11}$ & $\left(\mathrm{C}_{8} \mathrm{H}_{16} \mathrm{BrCuN}_{6} \mathrm{O}_{2}^{+}\right)_{2} \cdot\left(\mathrm{Cu}_{3} \mathrm{Br}_{5}^{2-}\right)$ \\
\hline Formula weight & 508.72 & 1333.57 \\
\hline Temperature $(\mathrm{K})$ & 150 & 150 \\
\hline Space group & Monoclinic, $P 2_{l} / n, Z=8$ & Monoclinic, $P 2_{l} / n, Z=4$ \\
\hline \multicolumn{3}{|l|}{ Unit cell dimensions } \\
\hline$a(\AA)$ & $15.6432(1)$ & $11.9172(1)$ \\
\hline$b(\AA)$ & $13.3892(1)$ & $11.1891(1)$ \\
\hline$c(\AA)$ & $18.7237(1)$ & $26.7601(2)$ \\
\hline$\alpha\left(^{\circ}\right)$ & 90 & 90 \\
\hline$\beta\left(^{\circ}\right)$ & $110.7881(7)$ & $99.3920(6)$ \\
\hline$\gamma\left({ }^{\circ}\right)$ & 90 & 90 \\
\hline$V\left(\AA^{3}\right)$ & $3666.37(4)$ & $3520.43(5)$ \\
\hline$F(000)$ & 2072 & 2536 \\
\hline$D_{\text {Calc }}\left(\mathrm{g} \mathrm{cm}^{-3}\right)$ & 1.843 & 2.516 \\
\hline Crystal size (mm) & $0.24 \times 0.08 \times 0.06$ & $0.32 \times 0.09 \times 0.01 \mathrm{~mm}$ \\
\hline$\mu\left(\mathrm{mm}^{-1}\right)$ & 5.03 & 13.03 \\
\hline$\theta$ range $\left(^{\circ}\right)$ & $3-74$ & $4-74$ \\
\hline \multirow[t]{3}{*}{ Limiting indices } & $-15 \leq h \leq 19$ & $-14 \leq h \leq 14$ \\
\hline & $-16 \leq k \leq 16$ & $-12 \leq k \leq 13$ \\
\hline & $-23 \leq l \leq 23$ & $-33 \leq l \leq 33$ \\
\hline No. of unique reflns & 7436 & 7102 \\
\hline No. of parameters & 609 & 397 \\
\hline$R\left[F^{2}>2 \sigma\left(F^{2}\right)\right]$ & 0.034 & 0.041 \\
\hline $\mathrm{w} \mathrm{R}\left(F^{2}\right)$ (all data) & $0.089^{*}$ & $0.106^{* *}$ \\
\hline$S$ & 1.00 & 0.99 \\
\hline \multicolumn{3}{|c|}{${ }^{*} w=1 /\left[\sigma^{2}\left(F^{2}\right)+(0.05 P)^{2}+4.48 P\right]$, where $P=\left(\max \left(F_{\mathrm{o}}^{2}, 0\right)+2 F_{\mathrm{c}}^{2}\right) / 3$} \\
\hline \multicolumn{3}{|c|}{${ }^{* *}$ Method Chebyshev polynomial, [weight] $=1.0 /\left[A_{0} * T_{0}(x)+A_{1} * T_{1}(x) \ldots+\left(A_{n-1}\right) * T_{n-1}(x)\right]$} \\
\hline \multicolumn{3}{|c|}{ Method robust weighting, $W=[$ weight $] *\left[1-(\operatorname{delta} F / 6 * \operatorname{sigma} F)^{2}\right]^{2}$} \\
\hline where $A_{\mathrm{i}}=0.226 E+$ & $40.233 E+04974.219$ and & \\
\hline
\end{tabular}


the semicarbazone ligand ( $1 \mathrm{mmol}, 0.228 \mathrm{~g}$ ) in methanol $(30 \mathrm{~mL})$, and the reaction mixture was stirred at room temperature for $3 \mathrm{~h}$.

$\left[\mathrm{CuL}\left(\mathrm{H}_{2} \mathrm{O}\right)\right]\left(\mathrm{ClO}_{4}\right)_{2}, \mathbf{1}$. The solution turned a bluegreen color. The solution was filtered, and the clear blue-green filtrate was left in a beaker to allow slow evaporation of the solvent. Analytically pure complex 1 precipitated out as a green powder. Blue-green prism crystals suitable for X-ray crystallography were obtained from acetone/2-propanol (2:1 v/v). Yield: $83 \%$. Anal. Calc. for $\mathrm{C}_{8} \mathrm{H}_{18} \mathrm{Cl}_{2} \mathrm{CuN}_{6} \mathrm{O}_{11}: \mathrm{C}, 18.89 ; \mathrm{H}, 3.57 ; \mathrm{N}, 16.52 \%$. Found: C, $19.06 ; \mathrm{H}, 3.55 ; \mathrm{N}, 16.55 \%$. IR $\left(\mathrm{KBr}, \mathrm{cm}^{-1}\right)$ : $v \mathrm{C}=\mathrm{N}=1556, v \mathrm{C}=\mathrm{O}=1649$. UV-Vis, $\lambda_{\max }(\mathrm{DMF}) / \mathrm{nm}$, $(\log \varepsilon): 725$ (1.88) and 360 (2.10).

$[\mathrm{CuLCI}] \mathrm{Cl} . \mathrm{H}_{2} \mathrm{O}, \mathbf{2}$. The solution turned a green color. The resultant suspension was filtered, washed with methanol and dried in air. Several attempts were made to obtain crystals, using various techniques, but the resultant crystals were always small and of poor quality. Yield: $37 \%$. Anal. Calc. for $\mathrm{C}_{8} \mathrm{H}_{18} \mathrm{Cl}_{2} \mathrm{CuN}_{6} \mathrm{O}_{3}: \mathrm{C}, 25.24 ; \mathrm{H}, 4.77 ; \mathrm{N}, 22.07 \%$. Found: $\mathrm{C}$, 25.27; H, 4.79; N, 22.26\%. IR ( KBr, $\left.\mathrm{cm}^{-1}\right): \mathrm{vC}=\mathrm{N}=1544$, $\mathrm{vC}=\mathrm{O}=1645$. UV-Vis, $\lambda_{\max }(\mathrm{DMF}) / \mathrm{nm},(\log \varepsilon): 986$ (2.19), 428(sh) (3.16) and 373(sh) (3.49).

$[\mathbf{C u L B r}]_{2} \mathbf{C u}_{3} \mathbf{B r}_{5}, 3$. The solution was filtered, and the clear green filtrate was kept in a beaker to allow slow evaporation of the solvent. The analytically pure complex $\mathrm{CuLBr}_{2}$. $\mathrm{H}_{2} \mathrm{O}$ precipitated out. The green powder which was obtained was filtered, washed with methanol and dried in air. Yield: 73\%. Anal. Calc. for $\mathrm{C}_{8} \mathrm{H}_{18} \mathrm{Br}_{2} \mathrm{CuN}_{6} \mathrm{O}_{3}: \mathrm{C}, 20.46 ; \mathrm{H}, 3.86$; $\mathrm{N}, 17.90 \%$. Found: C, 20.68; H, 3.79; N, 17.73\%.

Upon recrystallized from methanol/2-propanol $(2: 1 \mathrm{v} / \mathrm{v})$, blue-green crystal was obtained which was filtered, washed with 2-propanol and dried in air. From this sample, several long, thin needles were studied by single-crystal $\mathrm{X}$-ray crystallography and proved to be $[\mathrm{CuLBr}]_{2} \mathrm{Cu}_{3} \mathrm{Br}_{5}, 3$. IR $(\mathrm{KBr}$, $\left.\mathrm{cm}^{-1}\right): \mathrm{vC}=\mathrm{N}=1543, \mathrm{vC}=\mathrm{O}=1674$. UV-Vis, $\lambda_{\max }(\mathrm{DMF}) /$ $\mathrm{nm},(\log \varepsilon): 983$ (2.77) and 353 (3.22).

Other crystals from this sample gave a different diffraction pattern, which was unfortunately always of very poor quality. The structure appears to be $[\mathrm{CuLBr}] \mathrm{Br} . \mathrm{H} 2 \mathrm{O}$, but there is massive disorder of the water molecule, the anion, and even the cation, and the refinement was not of publishable standard.

$\left[\mathrm{CuLH}_{2} \mathrm{O}\right]\left(\mathrm{NO}_{3}\right)_{2}, 4$. The solution was filtered, and the clear green filtrate was kept in a beaker to allow the solvent to slowly evaporate. Analytically pure complex 4 precipitated out. The green powder which was obtained was filtered, washed with methanol and dried in air. Several attempts to prepare single crystals of $\mathrm{X}$-ray quality were unsuccessful. Yield: $84 \%$. Anal. Calc. for $\mathrm{C}_{8} \mathrm{H}_{18} \mathrm{CuN}_{8} \mathrm{O}_{9}$ : C, 22.15; H, 4.18; N, 25.83\%. Found: C, 21.67; H, 4.17; $\mathrm{N}, 26.15 \%$. I IR $\left(\mathrm{KBr}, \mathrm{cm}^{-1}\right)$ : $\mathrm{vC}=\mathrm{N}=1563, \mathrm{vC}=\mathrm{O}=1648$. UV-Vis, $\lambda_{\max }(\mathrm{DMF}) / \mathrm{nm},(\log \varepsilon): 738$ (1.83) and 374 (2.84).

\section{Results and discussion}

\section{Syntheses and characterization of the complexes}

The tetradentate semicarbazone ligand was obtained by condensation of semicarbazide hydrochloride and 2,5-hexadione at room temperature in an aqueous solution. Copper(II) complexes 1-4 were obtained by reacting the ligand with the corresponding $\mathrm{Cu}(\mathrm{II}) \mathrm{X}_{2}$ salt in equimolar ratio at room temperature in methanol solvent.

The complexes have low stability as a seven-member chelate ring is formed (vide infra). The size effect of the chelate ring on complexes stability has been reported previously [26-29], where it has been shown that the complex stability decreases as the chelate ring size increase so that seven-member chelated rings lead to less stable complexes than five- and six-member chelate rings.

The reaction of the semicarbazone ligand with $\mathrm{CuBr}_{2}$ results in the formation of the complex $[\mathrm{CuLBr}] \mathrm{Br} . \mathrm{H}_{2} \mathrm{O}$. Upon recrystallization, blue-green crystals of this compound were obtained, but they were not of sufficient quality to give X-ray diffraction data leading to a publishable structure. The attempted refinement did, however, firmly suggest that the structure was, indeed, $[\mathrm{CuLBr}] \mathrm{Br} . \mathrm{H}_{2} \mathrm{O}$.

Other blue-green crystals from this sample were shown by single-crystal $\mathrm{X}$-ray crystallography to be $[\mathrm{CuLBr}]_{2} \mathrm{Cu}_{3} \mathrm{Br}_{5}$, and refinement of the structure was satisfactory (vide infra). The $\mathrm{Cu}_{3} \mathrm{Br}_{5}^{2-}$ anion appears to have increased the stability of the $[\mathrm{CuLBr}]^{+}$complex and helped the growth of suitable crystals. The above observations suggest that the solvent methanol and 2-propanol play a role in for the reduction of copper(II) to copper(I) in the presence of the $\mathrm{Br}^{-}$anion. It is interesting that the reduction process was observed in an aerobic situation.

Complex 2 only yielded poor-quality crystals, and a structure determination attempt gave unsatisfactory results. The existence of $[\mathrm{CuLCl}] \mathrm{Cl}$ did appear to be observed in the partial refinement, however.

Preparation of single crystals of complex 4 suitable for X-ray analysis was unsuccessful. However, on the basis of the similarity of the spectroscopic properties of $\mathbf{4}$ with complex 1, $\left[\mathrm{CuL}\left(\mathrm{H}_{2} \mathrm{O}\right)\right]\left(\mathrm{ClO}_{4}\right)_{2}$, for which the crystal structure has been determined (vide infra), it can be inferred that $\mathbf{4}$ has similar structure to that of $\mathbf{1}$ complex, i.e., $\left[\mathrm{CuL}\left(\mathrm{H}_{2} \mathrm{O}\right)\right]\left(\mathrm{NO}_{3}\right)_{2}$.

Besides elemental analysis, all the complexes were initially characterized by infrared spectral. A comparison of the spectra of the free ligand and complexes indicates that the ligand is coordinated to the copper center. The IR spectrum of the free semicarbazone ligand shows bands at 1581 and $1683 \mathrm{~cm}^{-1}$, which are assigned as $\nu \mathrm{C}=\mathrm{N}$ and $\nu \mathrm{C}=\mathrm{O}$, respectively. In the copper complexes, the strong 
$\nu \mathrm{C}=\mathrm{N}$ and $\nu \mathrm{C}=\mathrm{O}$ bands are shifted toward lower energy in comparison with the free ligand, which indicates coordination of the imine nitrogen atom and carbonyl group to the copper ion [24, 30].

The semicarbazone ligand $\mathrm{L}$ is insoluble in most common organic solvents and also is only very slightly soluble in DMF, since the almost complete insolubility of the ligand made it impossible to obtain a UV-Vis spectrum.

The electronic spectra of the copper complexes 1-4 in DMF show a broad band at 725, 986, 983 and $738 \mathrm{~nm}$ which arise from a spin-allowed $d-d$ transition of copper(II) $\left(d^{9}\right.$ electronic configuration), respectively. The copper(II) complexes exhibit a strong bond in the UV region (353-428 nm) which could be attributed to charge transfer transition [18, 19].

\section{X-ray crystal structures}

\section{Description of the complex 1}

Single crystals of complex 1 suitable for X-ray were obtained from acetone/2-propanol. The complex crystallized in the monoclinic space group $P 2_{1} / n$. The crystallographic asymmetric unit consists of two independent $\left[\mathrm{CuL}\left(\mathrm{H}_{2} \mathrm{O}\right)\right]^{2+}$ cations and four perchlorate anions. Both cations show coordination of the copper(II) to the semicarbazone ligand and to a water molecule. There is disorder in the locations of some oxygen atoms of two of the perchlorate anions. The $\left[\mathrm{CuL}\left(\mathrm{H}_{2} \mathrm{O}\right)\right]^{2+}$ cation is monomeric with a tetradentate neutral ligand and a water molecule coordinated to the $\mathrm{Cu}$ atom. There is a small difference between the two independent cations: for one, there is weak interaction between $\mathrm{Cu} 1$ and a disordered oxygen atom of a neighboring perchlorate anion, while for $\mathrm{Cu} 2$, there is no such interaction. The structure of the cation with the labeling of selected atoms is shown in Fig. 1. Selected bond lengths and angles are
Table 2 Selected bond lengths $(\AA)$ and angles $\left({ }^{\circ}\right)$ in complexes 1 and 3

\begin{tabular}{|c|c|c|c|}
\hline \multicolumn{4}{|l|}{ Complex 1} \\
\hline $\mathrm{Cu} 1-\mathrm{O} 1$ & $1.9371(15)$ & $\mathrm{Cu} 2-\mathrm{O} 4$ & $1.9362(15)$ \\
\hline $\mathrm{Cu} 1-\mathrm{O} 2$ & $1.9669(15)$ & $\mathrm{Cu} 2-\mathrm{O} 5$ & $1.9677(15)$ \\
\hline $\mathrm{Cu} 1-\mathrm{O} 3$ & $2.2048(17)$ & $\mathrm{Cu} 2-\mathrm{O} 6$ & $2.2181(18)$ \\
\hline $\mathrm{Cu} 1-\mathrm{N} 3$ & $2.0385(18)$ & $\mathrm{Cu} 2-\mathrm{N} 9$ & $2.0286(18)$ \\
\hline Cu1-N4 & $1.9692(18)$ & $\mathrm{Cu} 2-\mathrm{N} 10$ & $1.9827(18)$ \\
\hline $\mathrm{Cu} 1 \cdots \mathrm{O} 12$ & $2.813(6)$ & $\mathrm{Cu} 2 \cdots \mathrm{O} 15$ & $3.070(2)$ \\
\hline $\mathrm{O} 1-\mathrm{Cu} 1-\mathrm{O} 2$ & $89.36(6)$ & $\mathrm{O} 4-\mathrm{Cu} 2-\mathrm{O} 5$ & $88.99(6)$ \\
\hline O1-Cu1-O3 & $93.50(7)$ & $\mathrm{O} 4-\mathrm{Cu} 2-\mathrm{O} 6$ & $92.62(7)$ \\
\hline O1-Cu1-N4 & $166.26(7)$ & O4-Cu2-N10 & $139.59(7)$ \\
\hline N3-Cu1-N4 & $103.51(7)$ & N9-Cu2-N10 & $105.68(7)$ \\
\hline O1-Cu1-N3 & $82.11(7)$ & O4-Cu2-N9 & $82.14(7)$ \\
\hline \multicolumn{4}{|l|}{ Complex 3} \\
\hline Cu1-O1 & $1.931(3)$ & $\mathrm{Cu} 2-\mathrm{O} 3$ & $1.917(4)$ \\
\hline $\mathrm{Cu} 1-\mathrm{O} 2$ & $1.970(4)$ & $\mathrm{Cu} 2-\mathrm{O} 4$ & $1.977(3)$ \\
\hline $\mathrm{Cu} 1-\mathrm{N} 3$ & $2.031(4)$ & $\mathrm{Cu} 2-\mathrm{N} 9$ & $2.056(4)$ \\
\hline Cu1-N4 & $1.968(4)$ & $\mathrm{Cu} 2-\mathrm{N} 10$ & $1.965(4)$ \\
\hline $\mathrm{Cu} 1-\mathrm{Br} 1$ & $2.7271(9)$ & $\mathrm{Cu} 2-\mathrm{Br} 2$ & $2.6791(9)$ \\
\hline $\mathrm{Cu} 3-\mathrm{Br} 3$ & $2.4359(10)$ & $\mathrm{Cu} 3-\mathrm{Br} 5$ & $2.5471(11)$ \\
\hline $\mathrm{Cu} 4-\mathrm{Br} 7$ & $2.4659(10)$ & $\mathrm{Cu} 4-\mathrm{Br} 5$ & $2.5756(13)$ \\
\hline $\mathrm{Cu} 5-\mathrm{Br} 7$ & $2.3518(10)$ & $\mathrm{Cu} 5-\mathrm{Br} 6$ & $2.9939(9)$ \\
\hline $\mathrm{Cu} 3 \cdots \mathrm{Cu} 4$ & $2.7126(12)$ & $\mathrm{Cu} 4 \cdots \mathrm{Cu} 5$ & $2.8351(13)$ \\
\hline $\mathrm{O} 1-\mathrm{Cu} 1-\mathrm{O} 2$ & $88.94(15)$ & $\mathrm{O} 3-\mathrm{Cu} 2-\mathrm{O} 4$ & $89.80(14)$ \\
\hline O1-Cu1-N3 & $82.87(15)$ & O3-Cu2-N9 & $82.38(15)$ \\
\hline O1-Cu1-N4 & $169.04(16)$ & $\mathrm{O} 3-\mathrm{Cu} 2-\mathrm{N} 10$ & $169.22(16)$ \\
\hline N3-Cu1-N4 & $102.92(16)$ & N9-Cu2-N10 & $102.37(16)$ \\
\hline Br1-Cu1-O1 & $96.43(11)$ & $\mathrm{Br} 2-\mathrm{Cu} 2-\mathrm{O} 3$ & $96.14(11)$ \\
\hline Br1-Cu1-N3 & $102.34(12)$ & $\mathrm{Br} 2-\mathrm{Cu} 2-\mathrm{N} 9$ & $106.52(12)$ \\
\hline $\mathrm{Br} 3-\mathrm{Cu} 3-\mathrm{Br} 5$ & $112.96(4)$ & $\mathrm{Br} 3-\mathrm{Cu} 3-\mathrm{Br} 4^{\mathrm{a}}$ & $105.33(4)$ \\
\hline $\mathrm{Br} 5-\mathrm{Cu} 4-\mathrm{Br} 6$ & $102.13(3)$ & $\mathrm{Br} 3-\mathrm{Cu} 3-\mathrm{Br} 5$ & $110.06(4)$ \\
\hline $\mathrm{Br} 6-\mathrm{Cu} 4-\mathrm{Br} 7$ & 95.99(4) & $\mathrm{Br} 7-\mathrm{Cu} 4-\mathrm{Br} 6^{\mathrm{b}}$ & $107.48(4)$ \\
\hline
\end{tabular}

Symmetry code: $a,-x+2,-y+2,-z+1 ; b,-x+1,-y+2,-z+1$
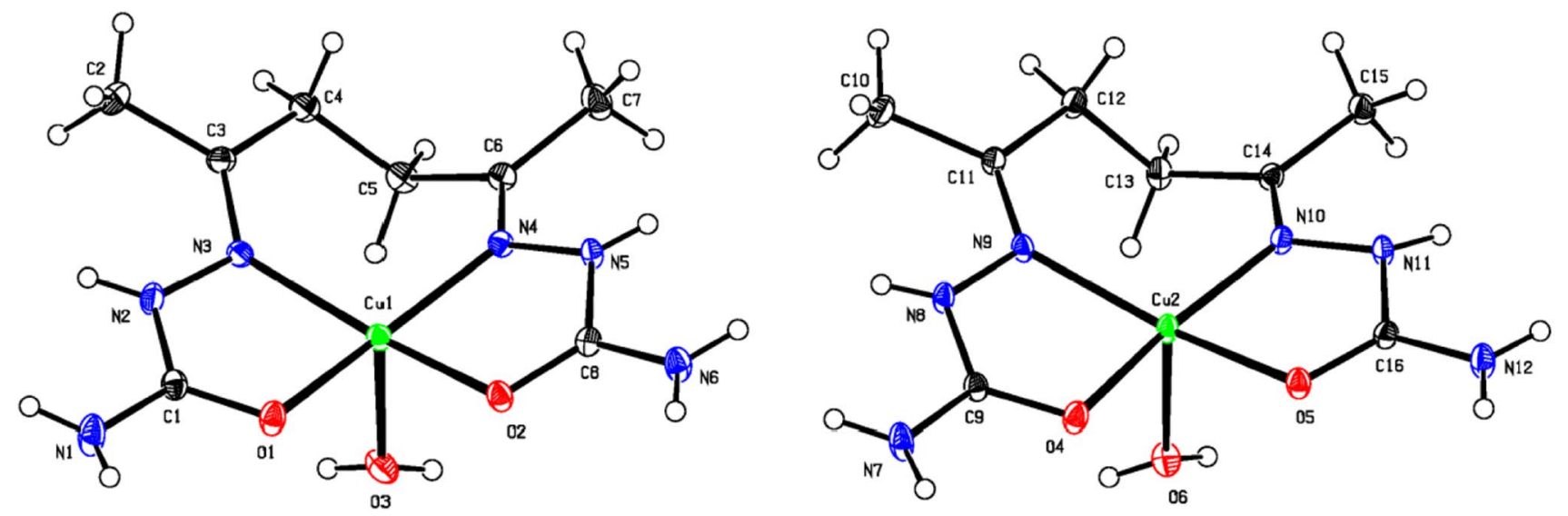

Fig. 1 The molecular structure of $\left[\mathrm{CuL}\left(\mathrm{H}_{2} \mathrm{O}\right)\right]^{2+}$ cations 1 with labeling of selected atoms 
listed in Table 2. The copper(II) centers are five-coordinated with a $\mathrm{N}_{2} \mathrm{O}_{3}$ donor set from the semicarbazone ligand and a water molecule. The coordination spheres of the copper atoms in the complex are best described as distorted square pyramids with the water molecule apical. The Addison parameter $\tau$ values are 0.08 (for $\mathrm{Cu} 1$ ) and 0.18 (for $\mathrm{Cu} 2$ ), where the parameter $\tau$ is defined as $\tau=(\alpha-\beta) / 60, \alpha>\beta$, where $\alpha$ and $\beta$ are the largest angles, with $\tau=1$ for a regular trigonal bipyramid and $\tau=0$ for a regular square pyramid [31]. The $\mathrm{Cu}-\mathrm{O}$ and $\mathrm{Cu}-\mathrm{N}$ bond lengths in the equatorial plane are in the range of 1.9362(15)-1.9677(15) $\AA$ and 1.9692(18)-2.0385(18) A, respectively (Table 2), which are agreement with similar compound [32-34].

The apical oxygen atoms show longer $\mathrm{Cu}-\mathrm{O}$ bond lengths (2.2048(17), for $\mathrm{Cu} 1$ and 2.2381(18) $\AA$, for $\mathrm{Cu} 2$ ) than the equatorial oxygen atoms $[32,34-36]$. The elongation of the $\mathrm{Cu}-\mathrm{O}$ axial bonds is due to a pseudo-Jahn-Teller distortion of the $d^{9}$ copper center. The lengths of the bonds between the copper atoms and the donor atoms are within the range of values normally found for such systems [32, 33, 37-39]. The copper atoms $\mathrm{Cu} 1$ and $\mathrm{Cu} 2$ are displaced from the basal plane of $\mathrm{N}_{2} \mathrm{O}_{2}$ by 0.248 and $0.216 \AA$ toward the apical oxygen atom, respectively.

In the first $\left[\mathrm{CuL}\left(\mathrm{H}_{2} \mathrm{O}\right)\right]^{2+}$ cation, the distance between the copper atom $\mathrm{Cu} 1$ and the disordered oxygen atom of the perchlorate anion (O12, with an occupancy of 0.4) is 2.813(6) $\AA$ (Fig. 2) which is significantly longer than the typical $\mathrm{Cu}-\mathrm{O}$ covalent bond $(1.98 \AA)$, but it is shorter than the sum of the van der Waals radii $(2.92 \AA)$ [39]. This distance is within the range of 2.2-2.9 $\AA$, known for axial $\mathrm{Cu}-\mathrm{O}$ bonds [40, 41] and hence suggests that the oxygen of the perchlorate anion may weakly coordinate to the copper ion in an axial position.

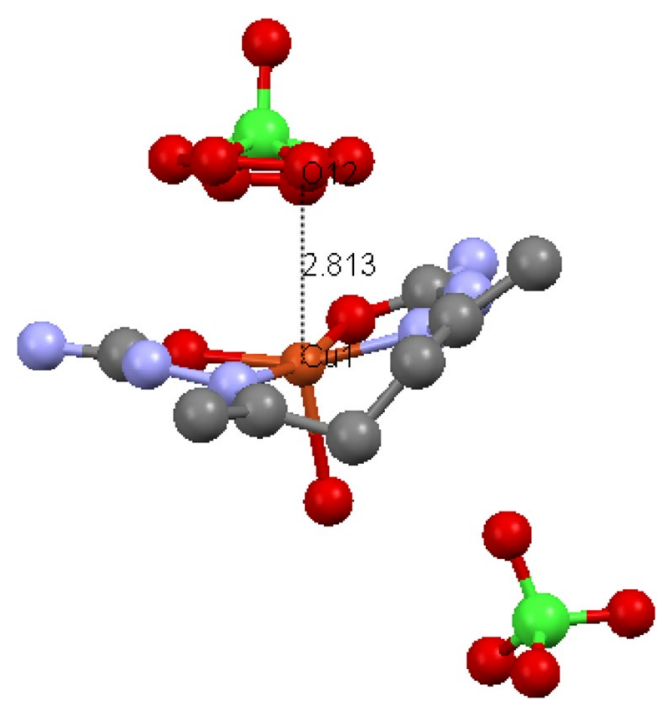

Fig. 2 The contacts between copper ion and the disordered oxygen atom of the perchlorate anion in complex $\mathbf{1}$
For the second cation, the shortest $\mathrm{Cu} 2 \cdots \mathrm{O}$ (perchlorate anion) distance is $3.070(2) \AA(\mathrm{Cu} 2 \cdots \mathrm{O} 15)$, which indicates the absence of any interaction between the copper center and perchlorate anion.

The oxygen atoms of the perchlorate anions are involved in intramolecular and intermolecular hydrogen bonding interaction with the hydrogen atoms of the coordinated water molecule, $\mathrm{NH}$ and $\mathrm{NH}_{2}$ groups of semicarbazone ligand. Also, there is an intermolecular hydrogen bonding between the hydrogen atoms of the $\mathrm{NH}_{2}$ groups of the semicarbazone ligand and the oxygen atom of a neighboring amide. Full details of the hydrogen bonding are given in Table 3.

\section{Description of the complex 3}

Suitable crystals of complex 3 for X-ray structure studies were obtained from methanol/2-propanol. The complex crystallized in the monoclinic space group $P 2_{1} / n$. The crystallographic asymmetric unit consists of two independent $[\mathrm{CuLBr}]^{+}$cations (copper centers labeled with $\mathrm{Cu} 1$ and $\mathrm{Cu} 2$ ) and $\mathrm{a}\left(\mathrm{Cu}_{3} \mathrm{Br}_{5}\right)^{2-}$ anion (copper centers labeled with $\mathrm{Cu} 3$, $\mathrm{Cu} 4$ and $\mathrm{Cu} 5$ ). The anions link to one another to form an infinite one-dimensional $\left(\mathrm{Cu}_{3} \mathrm{Br}_{5}^{2-}\right)_{\mathrm{n}}$ chain.

The molecular structure of the complex with the labeling of selected atoms is shown in Figs. 3 and 4. Selected bond lengths and angles are listed in Table 2.

The $[\mathrm{CuLBr}]^{+}$cations of complex 3 show copper(II) centers which are five-coordinated, with a $\mathrm{N}_{2} \mathrm{O}_{2}$ donor set from the semicarbazone neutral ligand and a apical $\mathrm{Br}^{-}$anion. The Addison parameters, $\tau$, are 0.20 and 0.25 for $\mathrm{Cu} 1$ and $\mathrm{Cu} 2$, respectively, which indicates a distorted square pyramid geometry. $\mathrm{Cu} 1$ and $\mathrm{Cu} 2$ are displaced from the basal plane of $\mathrm{N}_{2} \mathrm{O}_{2}$ by 0.257 and $0.282 \AA$ toward the apical $\mathrm{Br}$ anion, respectively. The $\mathrm{Cu}-\mathrm{Br}$ bond lengths are 2.7271(9) and 2.6791(9) $\AA$ for $\mathrm{Cu} 1$ and $\mathrm{Cu} 2$, respectively.

The $\mathrm{Cu}-\mathrm{O}$ and $\mathrm{Cu}-\mathrm{N}$ bond lengths in the equatorial plane are in the range of 1.917(4)-1.977(3) $\AA$ and 1.965(4)$2.056(4) \AA$, respectively, which are very similar to the corresponding distances in $\mathbf{1}$ (Table 2) and are in good agreement with analogous $\mathrm{Cu}(\mathrm{II})$ complexes observed in the literature [32-34].

In the $\left(\mathrm{Cu}_{3} \mathrm{Br}_{5}\right)^{2-}$ anion, each $\mathrm{Cu}(\mathrm{I})$ is bridged to two adjacent $\mathrm{Cu}$ by four $\mathrm{Br}^{-}$anions. $\mathrm{The} \mathrm{Cu}(\mathrm{I})$ center adopts a tetrahedral geometry with four $\mathrm{Br}^{-}$ligands. $\mathrm{The} \mathrm{Br}-\mathrm{Cu}-\mathrm{Br}$ bond angles are in the range 95.99(4)-123.60(4) ${ }^{\circ}$. The geometries of the copper atoms are best described as a tetrahedral with $\tau_{4}$ index $0.93,0.90$ and 0.74 for $\mathrm{Cu} 3$, $\mathrm{Cu} 4$ and $\mathrm{Cu} 5$, respectively. The parameter $\tau$ is defined as $\tau_{4}=\left[360^{\circ}-(\alpha+\beta)\right] / 141^{\circ}$, where $a$ and $b$ are the largest angles around the central metal in the complex; $\tau_{4}=1$ for a regular tetrahedron and $\tau_{4}=0$ for a regular square planar [42]. On the basis of the mode coordination of the $\mathrm{Br}^{-}$ligands ( $\mu_{2}$-bridging and $\mu_{3}$-bridging), there are three 
Table 3 Hydrogen bonding ( and angles $\left({ }^{\circ}\right)$ for complex 1

\begin{tabular}{|c|c|c|c|c|c|}
\hline $\mathrm{D}-\mathrm{H} \cdots A$ & D-H & $\mathrm{H} \cdots A$ & $\mathrm{D} \cdots A$ & $\mathrm{D}-\mathrm{H} \cdots A$ & Symmetry code \\
\hline $\mathrm{O} 3-\mathrm{H} 1 \cdots \mathrm{O} 8 *$ & $0.72(4)$ & $2.10(4)$ & $2.798(3)$ & $165(4)$ & $-x+3 / 2, y-1 / 2,-z+3 / 2$ \\
\hline $\mathrm{O} 3-\mathrm{H} 2 \cdots \mathrm{O} 10^{*}$ & $0.72(4)$ & $2.15(4)$ & $2.800(3)$ & $152(4)$ & $-x+3 / 2, y-1 / 2,-z+3 / 2$ \\
\hline $\mathrm{O} 3-\mathrm{H} 2 \cdots \mathrm{O} 23$ & $0.77(4)$ & $2.02(4)$ & $2.793(3)$ & $175(4)$ & \\
\hline 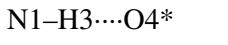 & $0.78(4)$ & $2.39(4)$ & $3.036(3)$ & $141(3)$ & $-x+3 / 2, y+1 / 2,-z+1 / 2$ \\
\hline 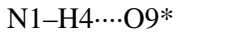 & $0.83(3)$ & $2.32(3)$ & $3.004(3)$ & $139(3)$ & $-x+3 / 2, y+1 / 2,-z+1 / 2$ \\
\hline $\mathrm{N} 1-\mathrm{H} 4 \cdots \mathrm{O} 11^{*}$ & $0.83(3)$ & $2.41(3)$ & $3.212(3)$ & $161(3)$ & $-x+3 / 2, y+1 / 2,-z+1 / 2$ \\
\hline $\mathrm{N} 2-\mathrm{H} 5 \cdots \mathrm{O} 13^{*}$ & $0.83(3)$ & $2.29(3)$ & $3.09(3)$ & $163(3)$ & $-x+3 / 2, y+1 / 2,-z+1 / 2$ \\
\hline $\mathrm{N} 5-\mathrm{H} 6 \cdots \mathrm{O} 22^{*}$ & $0.78(3)$ & $2.10(3)$ & $2.832(3)$ & $157(3)$ & $-x+3 / 2, y+1 / 2,-z+3 / 2$ \\
\hline $\mathrm{N} 6-\mathrm{H} 7 \cdots \mathrm{O} 22 *$ & $0.85(3)$ & $2.41(3)$ & $3.105(3)$ & $140(3)$ & $-x+3 / 2, y+1 / 2,-z+3 / 2$ \\
\hline N6-H7…N24* & $0.85(3)$ & $2.38(3)$ & $2.903(3)$ & $120(2)$ & $x-1 / 2,-y+1 / 2, z+1 / 2$ \\
\hline N6-H8…N21* & $0.73(3)$ & $2.35(3)$ & $3.067(3)$ & $166(3)$ & $-x+3 / 2, y+1 / 2,-z+3 / 2$ \\
\hline 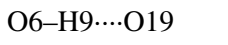 & $0.81(3)$ & $2.20(3)$ & $2.967(3)$ & $160(3)$ & \\
\hline O6-H9 $\cdots . \mathrm{O} 28$ & $0.81(3)$ & $2.11(3)$ & $2.725(3)$ & $133(3)$ & \\
\hline 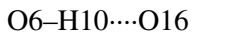 & $0.77(3)$ & $2.20(3)$ & $2.871(3)$ & $147(3)$ & \\
\hline N7-H11…O $1^{*}$ & $0.82(3)$ & $2.34(3)$ & $3.028(3)$ & $142(3)$ & $-x+1,-y+1,-z+1$ \\
\hline $\mathrm{N} 7-\mathrm{H} 11 \cdots \mathrm{O} 2 *$ & $0.82(3)$ & $2.55(3)$ & $3.110(3)$ & $127(3)$ & $-x+1,-y+1,-z+1$ \\
\hline $\mathrm{N} 7-\mathrm{H} 12 \cdots \mathrm{O} 21^{*}$ & $0.86(3)$ & $2.19(3)$ & $2.981(3)$ & $154(3)$ & $x-1 / 2,-y+1 / 2, z-1 / 2$ \\
\hline $\mathrm{N} 8-\mathrm{H} 13 \cdots \mathrm{O} 18 *$ & $0.78(3)$ & $2.25(3)$ & $2.982(3)$ & $159(3)$ & $x-1 / 2,-y+1 / 2, z-1 / 2$ \\
\hline $\mathrm{N} 8-\mathrm{H} 13 \cdots \mathrm{O} 26^{*}$ & $0.78(3)$ & $2.39(3)$ & $3.074(3)$ & $148(3)$ & $x-1 / 2,-y+1 / 2, z-1 / 2$ \\
\hline $\mathrm{N} 8-\mathrm{H} 13 \cdots \mathrm{O} 27 *$ & $0.78(3)$ & $2.55(3)$ & $3.023(3)$ & $120(3)$ & $-x+3 / 2, y+1 / 2,-z+1 / 2$ \\
\hline $\mathrm{N} 11-\mathrm{H} 14 \cdots \mathrm{O} 14 *$ & $0.84(3)$ & $2.10(3)$ & $2.921(3)$ & $166(3)$ & $x-1 / 2,-y+1 / 2, z+1 / 2$ \\
\hline 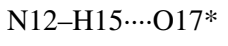 & $0.81(3)$ & $2.08(3)$ & $2.884(3)$ & 171(3) & $x-1 / 2,-y+1 / 2, z+1 / 2$ \\
\hline 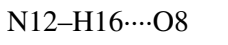 & $0.78(3)$ & $2.31(3)$ & $3.055(3)$ & $160(3)$ & \\
\hline N12-H16 …O11 & $0.78(3)$ & $2.26(3)$ & $3.013(3)$ & 161(3) & \\
\hline
\end{tabular}

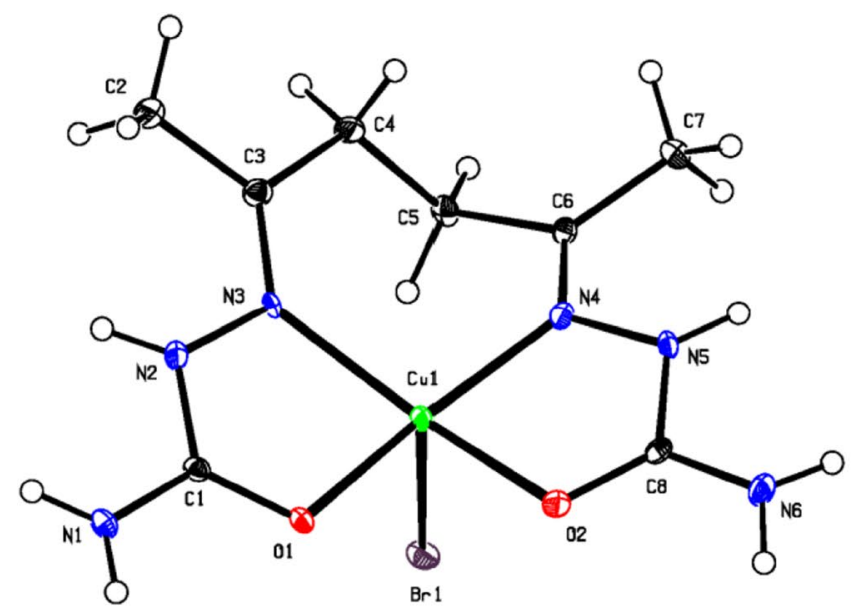

Fig. 3 The molecular structure of $[\mathrm{CuLBr}]^{+}$cations 3 with labeling of selected atoms

types of $\mathrm{Cu}(\mathrm{I})$ atoms, i.e., $\left[\mathrm{Cu} 3\left(\mu_{2}-\mathrm{Br}\right)_{3}\left(\mu_{3}-\mathrm{Br}\right)\right]$, $\left[\mathrm{Cu} 4\left(\mu_{2^{-}}\right.\right.$ $\left.\mathrm{Br})_{2}\left(\mu_{3}-\mathrm{Br}\right)_{2}\right]$ and $\left[\mathrm{Cu} 5\left(\mu_{2}-\mathrm{Br}\right)\left(\mu_{3}-\mathrm{Br}\right)_{3}\right]$. The average $\mathrm{Cu}-\mu_{3}-\mathrm{Br}$ distance is $2.643 \AA$ which is slightly longer than the $\mathrm{Cu}-\mu_{2}-\mathrm{Br}$ distance $(2.450 \AA$ ) $)$. The distances between adjacent $\mathrm{Cu}$-centers in the $\left(\mathrm{Cu}_{3} \mathrm{Br}_{5}\right)^{2-}$ anion are 2.7126(12)
$\AA$ for $\mathrm{Cu} 3 \cdots \mathrm{Cu} 4$ and $2.8351(13) \AA$ for $\mathrm{Cu} 4 \cdots \mathrm{Cu} 5$, which show no indication of attractive interactions between $\mathrm{Cu}$ centers [43]. A fragment of the polymeric structure of the $\left(\mathrm{Cu}_{3} \mathrm{Br}_{5}\right)^{2-}$ anion is shown in Fig. 4, and the bond lengths and valence angles are given in Table 2. 


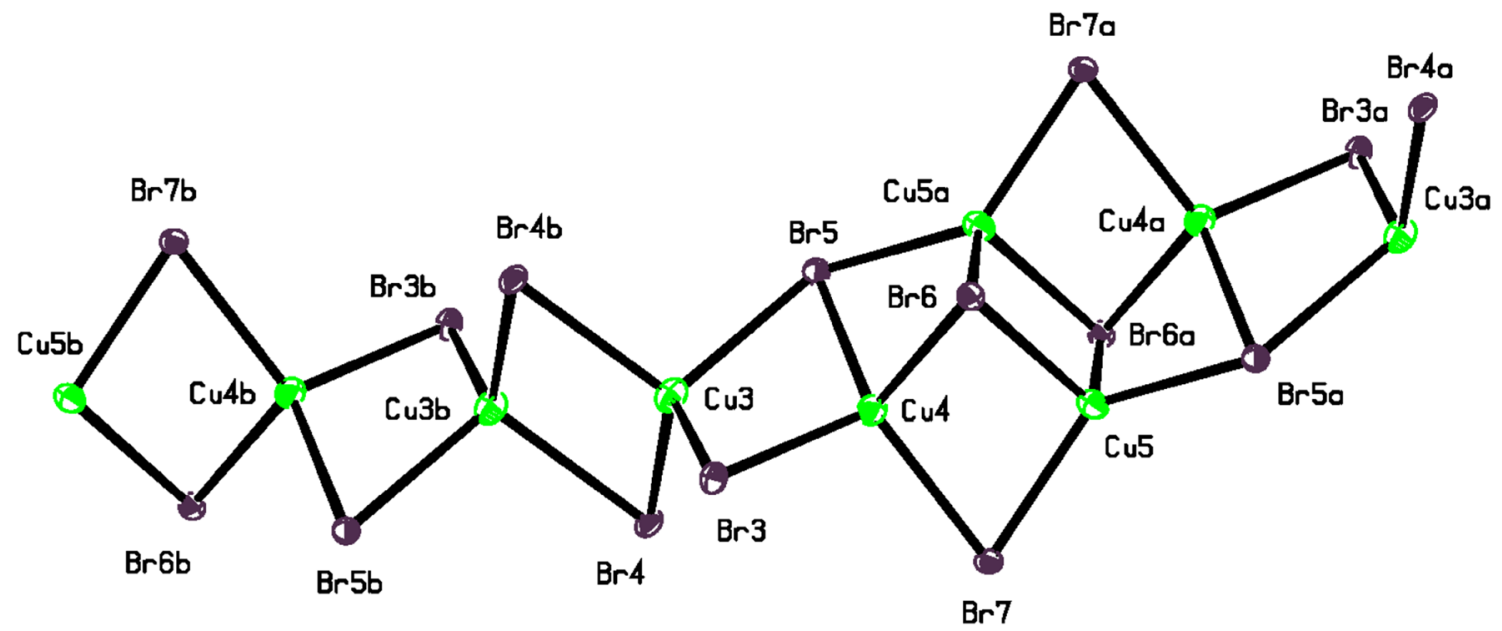

Fig. 4 The molecular structure of the $\left(\mathrm{Cu}_{3} \mathrm{Br}_{5}\right)^{2-}$ anion in $\mathbf{3}$ with labeling of selected atoms

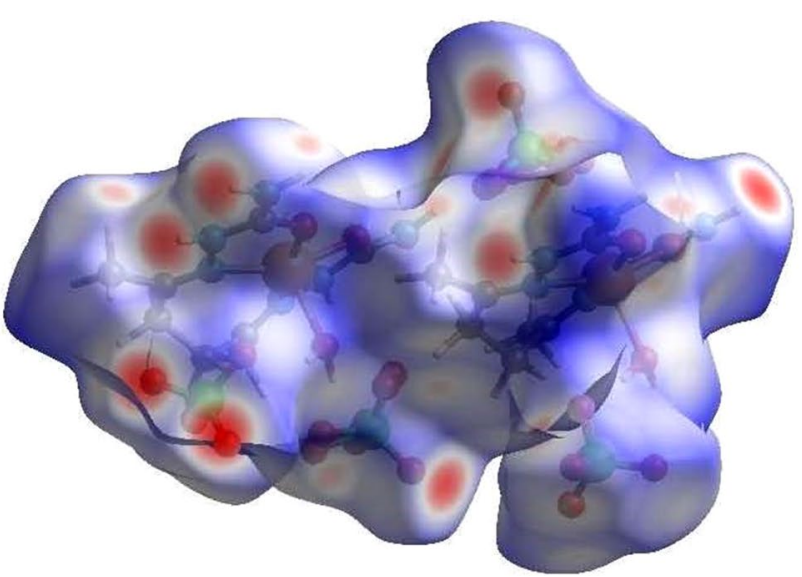

A

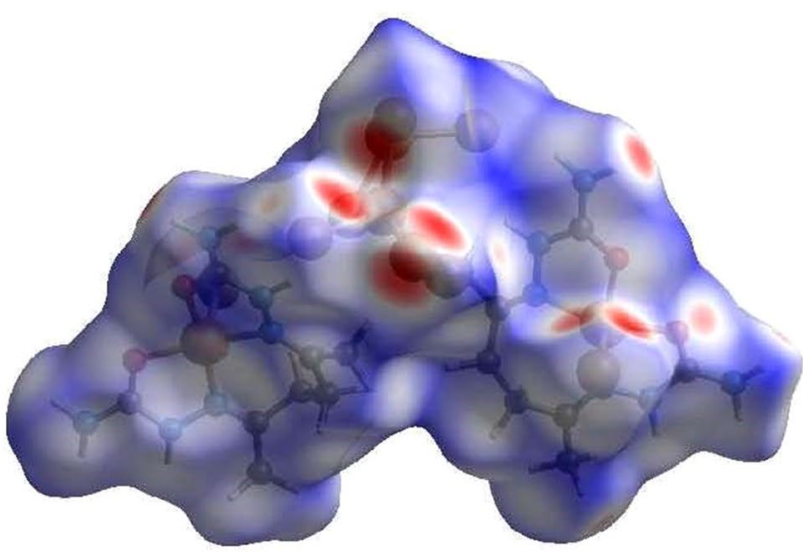

B

Fig. 5 Hirshfeld surface mapped with $d_{\text {norm }}$ for complexes 1 (a) and 3 (b)

\section{Hirshfeld surface analysis}

The Hirshfeld surface analysis and the fingerprint plots provide some useful quantitative information about the strength and role of the hydrogen bonds and other intermolecular contacts in the crystal packing. In Fig. 5, the 3D Hirshfeld surface mapped is shown over a $d_{\text {norm }}$ range of -0.512-1.471 and -0.512-1.350 $\AA$ for $\mathbf{1}$ and 3, respectively. The surface is shown as transparent to allow visualization of the molecular moiety. The circular depressions (deep red) visible on the surfaces are indicative of hydrogen bonding contacts, and the other color spots are indicative of the presence of other intermolecular interactions in the crystal packing. The 2D fingerprint plot and the contribution of each type of interaction for $\mathbf{1}$ and $\mathbf{3}$ are described in Fig. 6. The main intermolecular interaction in $\mathbf{1}$ are $\mathrm{O} / \mathrm{H}$ (64.1\%) and $\mathrm{H} / \mathrm{H}(19.3 \%)$ and in 2 are $\mathrm{Br} / \mathrm{H}$ (31.7\%) and $\mathrm{H} / \mathrm{H}(25.8 \%)$, which correspond to hydrogen bonds and the Van der Waals interactions.

\section{Conclusion}

A novel the tetradentate neutral ligand semicarbazone has been synthesized, and its coordination with different copper(II) salt has been studied. The crystal structures of two complexes have been determined by single-crystal $\mathrm{X}$-ray diffraction analyses. The structures of the complexes are influenced by the anions that are present. When $\mathrm{Cl}$ and $\mathrm{Br}$ anions were used, the anion can act as a ligand, and $[\mathrm{CuLX}]^{+}(\mathrm{X}=\mathrm{Cl}$ and $\mathrm{Br})$ cationic complexes were isolated. However, when the $\mathrm{Br}$ anion was used, copper(II) could be reduced to copper(I), and a $\mathrm{Cu}_{3} \mathrm{Br}_{5}^{2-}$ species could also be formed. When nitrate and perchlorate anions were used, a $\left[\mathrm{CuLH}_{2} \mathrm{O}\right]^{2+}$ cation complex was formed, and the nitrate and 

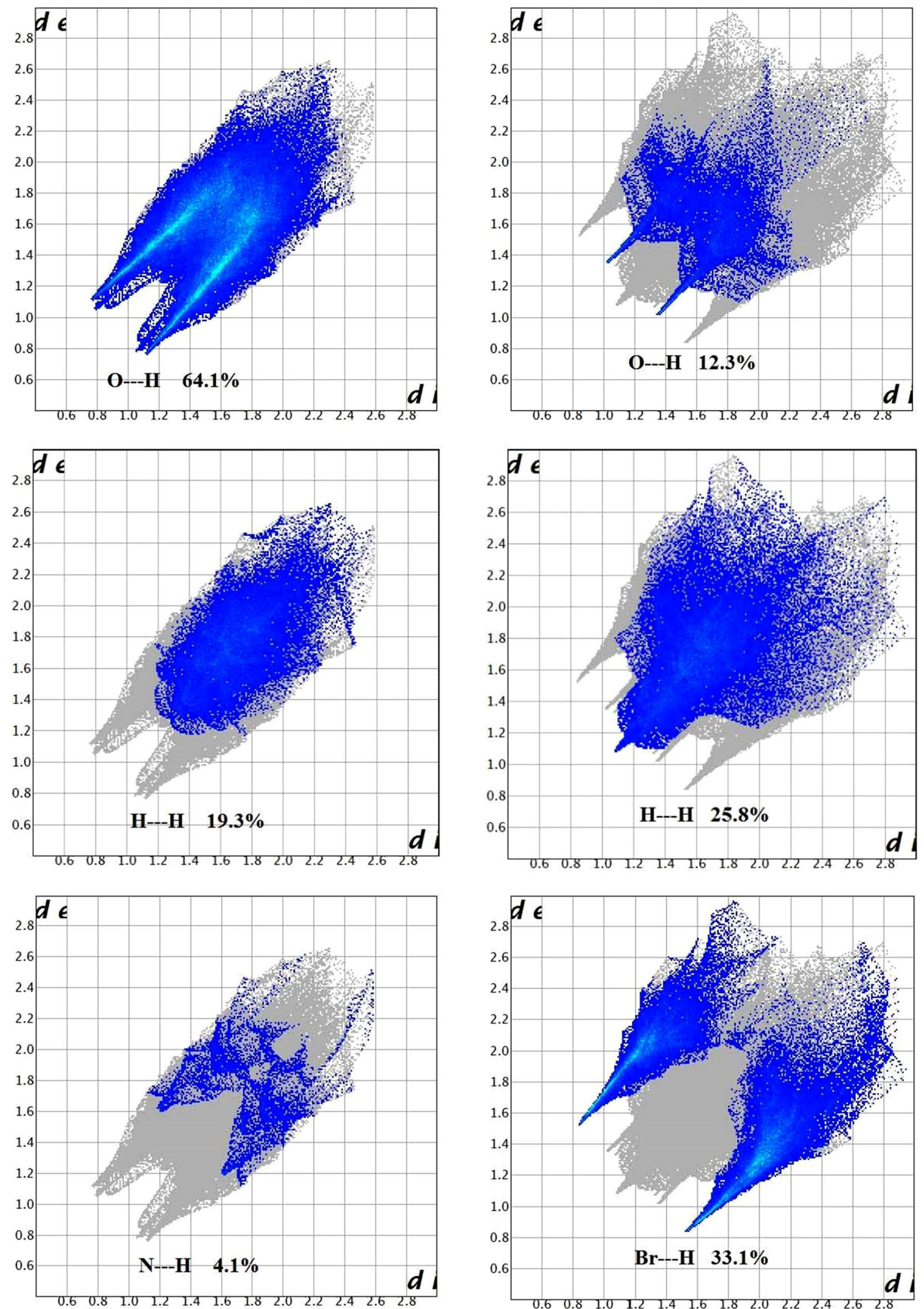

A

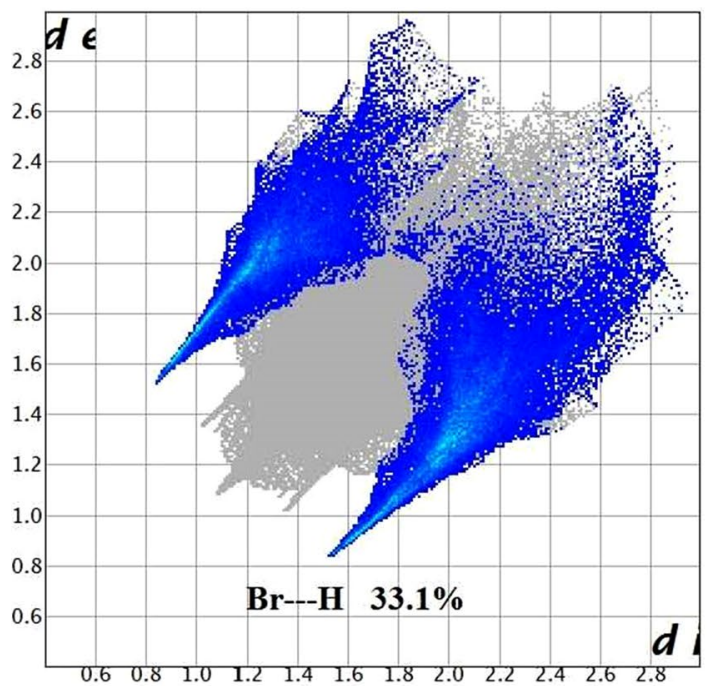

B

Fig. 6 The 2D fingerprint plots and relative contributions to the percentage of Hirshfeld surface for various interactions in $\mathbf{1}$ (a) and $\mathbf{3}$ (b) 
perchlorate act as a counter ions. The X-ray single crystal shows that the complexes $\mathbf{1}$ and $\mathbf{3}$ have square pyramidal geometry.

The Hirshfeld surface analysis was employed for $\mathbf{1}$ and $\mathbf{3}$, allowing quantification of the various interactions within the structures.

Acknowledgements The authors are grateful to the Yazd University and the Australian National University for partial support of this work.

\section{References}

1. D.G. Calatayud, E. López-Torres, M.A. Mendiola, Polyhedron 101, 133 (2015)

2. S. Janardan, P. Suman, G. Swapna, A. Amrita, R. Priya, R. Siva, K. Vijayakrishna, A. Sivaramakrishna, Appl. Biochem. Biotechnol. 173, 596 (2014)

3. S. Prasad, R.K. Agarwal, A. Kumar, J. Iran. Chem. Soc. 8, 825 (2011)

4. R. Vafazadeh, N. Abdollahi, A.C. Willis, Acta Chim. Slov. 64, 409 (2017)

5. T.A. Reena, E.B. Seena, M.R.P. Kurup, Polyhedron 27, 3461 (2008)

6. E. López-Torres, D.G. Calatayud, C.J. Pastor, M.A. Mendiola, Polyhedron 27, 2507 (2008)

7. A.A. Abou-Hussen, W. Linert, Synth. React. Inorg. 39, 570 (2009)

8. H. Chen, X.Q. Ma, Y. Lv, L. Jia, J. Xu, Y. Wang, Z. Ge, J. Mol. Struct. 1109, 146 (2016)

9. V. Jevtovic, D. Cvetkovic, D. Vidovicc, J. Iran. Chem. Soc. 8, 727 (2011)

10. R. Vafazadeh, N. Hasanzade, M.M. Heidari, A.C. Willis, Acta Chim. Slov. 62, 122 (2015)

11. S. Hasnain, M. Zulfequar, N. Nishat, J. Coord. Chem. 64, 952 (2011)

12. V.L. Siji, M.R. Sudarsanakumar, S. Suma, Polyhedron 29, 2035 (2010)

13. R. Vafazadeh, A.C. Willis, Acta Chim. Slov. 63, 186 (2016)

14. S. Chandra, Sangeetika, S. Thakur, Transit. Met. Chem. 29, 925 (2004)

15. E. López-Torres, U. Abram, Inorg. Chem. 47, 2890 (2008)

16. R.N. Butler, A.B. Hanahoe, A.M. O’Donohue, J. Chem. Soc. Perkin Trans. 1, 1246 (1979)

17. W. Caminati, J.U. Grabow, J. Am. Chem. Soc. 128, 854 (2006)

18. R. Vafazadeh, M. Alinaghi, A.C. Willis, A. Benvidi, Acta Chim. Slov. 61, 121 (2014)

19. R. Vafazadeh, F. Jafari, M.M. Heidari, A.C. Willis, J. Coord. Chem. 69, 1313 (2016)
20. Z. Otwinowski, W. Minor, in Methods in Enzymology, ed. by C.W. Carter Jr., R.M.W. Sweet (Academic Press, New York, 1997), pp. 307-326

21. A. Altomare, G. Cascarano, G. Giacovazzo, A. Guagliardi, M.C. Burla, G. Polidori, M. Camalli, J. Appl. Cryst. 27, 435 (1994)

22. P.W. Betteridge, J.R. Carruthers, R.I. Cooper, K. Prout, D.J. Watkin, J. Appl. Cryst. 36, 1487 (2003)

23. K. Wolff, D.J. Grimwood, J.J. McKinnon, M.J. Turner, D. Jayatilaka, M.A. Spackman. CrystalExplorer, Version 3.0. University of Western Australia (2012)

24. R. Vafazadeh, R. Esteghamat-Panah, A.C. Willis, A.F. Hill, Polyhedron 48, 51 (2012)

25. J. Patole, S. Dutta, S. Padhye, E. Sinn, Inorg. Chim. Acta 318, 207 (2001)

26. L.C. Nathan, J.E. Koehne, J.M. Gilmore, K.A. Hannibal, W.E. Dewhirst, T.D. Mai, Polyhedron 22, 887 (2003)

27. R. Vafazadeh, S. Bidaki, Acta Chim. Slov. 61, 153 (2014)

28. R. Vafazadeh, S. Bidaki, Acta Chim. Slov. 57, 310 (2010)

29. R.D. Hancock, Acc. Chem. Res. 23, 253 (1990)

30. M.T.H. Tarafder, A. Kasbollah, K.A. Crouse, A.M. Ali, B.M. Yamin, H.K. Fun, Polyhedron 20, 2363 (2001)

31. A.W. Addison, N. Rao, J. Reedijk, J.V. Rijn, G.C. Verschoor, J. Chem. Soc. Dalton Trans. 1349, 1356 (1984)

32. R. Vafazadeh, A.C. Willis, J. Coord. Chem. 68, 2240 (2015)

33. P. Bhowmik, N. Aliaga-Alcalde, V. Gómez, M. Corbella, S. Chattopadhyay, Polyhedron 49, 269 (2013)

34. R. Vafazadeh, Z. Moghadas, A.C. Willis, J. Coord. Chem. 68, 4255 (2015)

35. M.-L. Liu, M. Jiang, K. Zheng, Y.-T. Li, Z.-Y. Wu, C.-W. Yan, J. Coord. Chem. 67, 630 (2014)

36. J. Lakshmipraba, S. Arunachalam, R. Vijay Solomon, P. Venuvanalingam, J. Coord. Chem. 68, 1374 (2015)

37. J. Chakraborty, S. Thakurta, G. Pilet, D. Luneau, S. Mitra, Polyhedron 28, 819 (2009)

38. P. Mukherjee, M.G.B. Drew, M. Estrader, C. Diaz, A. Ghosh, Inorg. Chim. Acta 361, 161 (2008)

39. B. Cordero, V. Gómez, A.E. Platero-Prats, M. Revés, J. Echeverría, E. Cremades, F. Arragán, S. Alvares, Dalton Trans. 2832 (2008)

40. I.M. Procter, B.J. Hathaway, P. Nicholls, J. Chem. Soc. A, 1678 (1968)

41. R. Vafazadeh, A. Dehgany-Firouabadi, A.C. Willis, Acta Chim. Slov. 64, 686 (2017)

42. P. Seth, S. Ghosh, A. Figuerola, A. Ghosh, Dalton Trans. 43, 990 (2014)

43. M. Maekawa, K. Sugimoto, T. Okubo, T. Kuroda-Sowa, M. Munakata, Polyhedron 29, 2807 (2010) 